\title{
ENTRE OS CHEIROS E GARRAFADAS: O TRABALHO DAS VENDEDORAS DE CHEIRO NAS FEIRAS PÚBLICAS DE BELÉM-PA EM 1830-1890
}

\author{
Lucielma Lobato SILVA ${ }^{1}$ \\ Secretaria Estadual de Educação-SEDUC/PA \\ lucielma.lobato@gmail.com
}

Resumo: Este artigo versa sobre o trabalho desempenhado pelas vendedoras de ervas para produção de banho de cheiro e de produtos terapêuticos denominados "garrafadas" em Belém do Pará entre 1830 e 1890. Com isso, tem por objetivo de remontar, com base em documentos de jornais, atas e decretos, a historiografia a respeito das mulheres que trabalharam com ervas e garrafadas terapêuticas nas feiras públicas de Belém entre os anos 1830 e 1890, período em que grandes são os relatos de jornais sobre essa atividade profissional e suas relações conflituosas, e, assim, é capaz de trazer uma importante contribuição para a historiografia urbana desse período em Belém do Pará. Dessa forma, busco apresentar como se desenvolviam essas atividades profissionais que ratificam a presença de religiões de cunho afro ou pajelança desde o século XIX e como ocorriam os possíveis conflitos em torno dessa atividade profissional em Belém. Além de analisar a profissão das ganhadeiras sob uma óptica diferente de muitas outras vistas em diversas regiões do Brasil e mesmo no Pará, uma vez que a maioria dos estudos de referência sobre as ganhadeiras tem como proposta analisá-las sobre o viés alimentício, aqui a investigação se dá pelos olhos documentais voltados para o significado do trabalho e da simbolização do produto Banho de Cheiro, Ervas e Garrafadas fitoterápicas e propor uma relação entre essas vendas e a presença das religiões de matriz africana na Amazônia ou mesmo da própria Pajelança na região urbana, isto é, na metrópole da Amazônia.

Palavras-Chaves: Mulheres. Trabalho. Banho de cheiro. Garrafadas.

\begin{abstract}
This versa article on the work performed by the sellers of herbs to scent bath production and therapeutic products called "potions" in Belém do Pará from 1830 to 1890, it aims to revamp, based on newspaper documents, minutes and decrees, ie the historiography concerning women who worked with herbs and therapeutic potions in public fairs of Bethlehem between years 1830 to 1890, during which great are newspaper reports of this occupation and its conflicting relations, and, so is able to make an important contribution to the urban history of this period in Belém do Pará. Thus, I seek to present as were developing these professional activities that confirm the presence of african nature of religions, or shamanism since the nineteenth century and took place as possible conflicts around this occupation in Bethlehem. In addition to analyzing the profession of ganhadeiras under an optical unlike many other views in various regions of Brazil and even in Pará, since most of the reference studies on ganhadeiras is to analyze proposal -Las on food bias, this research is given by the documentary eye on the meaning of work and the symbolization smelling bath products, herbal potions and herbs and propose a relationship between these sales and the presence of religions of African origin in Amazon or even own shamanism in the urban area, that is, in the Amazon metropolis.
\end{abstract}

Key Words: Women. Work. Smell bath. Potions.

\footnotetext{
${ }^{1}$ Doutoranda em Antropologia Social pela Universidade Federal do Pará PPGA/UFPA, Mestra em Ciências da Religião pela Universidade do Estado do Pará, ministra a disciplina de História na Educação Básica do Estado do Pará, lucielma.lobato@gmail.com.
} 


\section{Introdução}

$\mathrm{Na}$ historiografia brasileira, muito se discutiu acerca dos trabalhos desempenhados pelas chamadas ganhadeiras $^{2}$, desde o século XVIII até períodos que se estendem da pós-abolição aos dias atuais. Essas atividades, de grande valia social e econômica, foram desenvolvidas em várias regiões do Brasil e possibilitaram, além do enriquecimento para algumas mulheres, também o reconhecimento de honradez e a valorização familiar pelo aspecto financeiro, pois, em alguns casos, elas eram arrimo da família.

Segundo Soares (1996), as relações escravistas nas ruas de Salvador do século XIX se caracterizavam pelo sistema de ganho. No ganho de rua, principalmente através do pequeno comércio, a mulher negra ocupou lugar destacado no mercado de trabalho urbano. Encontramos tanto mulheres escravas colocadas no ganho por seus proprietários, quanto mulheres negras livres e libertas que lutavam para garantir o seu sustento e de seus filhos.

No período pós-abolição, as libertas comercializavam produtos como hortaliças, verduras, peixes, frutas, comida pronta, fazendas e louças. Embora não formassem um grupo homogêneo, as vendedeiras conseguiam mais facilmente integrar-se no pequeno comércio urbano, retirando desses negócios o necessário para a sobrevivência e até alcançando alguma prosperidade. Certas posições ocupadas nesse pequeno comércio obtinham uma margem de lucro bastante generosa.

Essas atividades profissionais não começaram a ser desenvolvidas recentemente, ao contrário, elas remontam a Salvador, no Estado da Bahia, desde os fins do século XVIII, no Maranhão e Rio de Janeiro, em meados do século XIX (VERGER, 1986). Em quase todos os estudos, é possível ver a capacidade gigante de as mulheres ganhadeiras trabalharem e adquirirem quantidades significativas de bens materiais, que lhes possibilitavam certa ostentação, especialmente no que tange às suas vestimentas, e inclusive ao sustentáculo religioso (LANDES, 2002).

No Brasil, os estudos que analisaram questões referentes à população negra, em sua maioria, demonstravam o negro como destituído de tudo ou como mercadoria, que, no limite, é quase a mesma coisa. Em outras palavras, o olhar era externo, mais do que isso, era o do colonizador, sobretudo do traficante e do "senhor". O africano, ao contrário, continuou tanto como criatura, quanto como criador. Dessa forma, durante a escravidão, na subalternidade, o "movimento das feiras" ocorria em várias direções, iluminando outra visão da diáspora, anulando o caminho sem volta de uma única direção.

Canevacci (1996, p. 08) salienta que uma das características fundamentais é a diáspora, uma criatividade que permite, de forma às vezes desordenada, fecundações inesperadas. Essa desordem promove, sem dúvida alguma, uma possibilidade sincrética que estará presente em todas as fecundações culturais, que, por sua vez, referem-se também a fatores históricos e socioeconômicos.

\footnotetext{
${ }^{2}$ Também chamadas de quitandeiras. 
O sincretismo faz-se presente desde o momento em que o africano foi brutalmente retirado de sua terra natal. Era parte das estratégias do sistema escravocrata a mistura de diferentes etnias para, assim, evitar rebeliões. Esse procedimento também ocorria na chegada dos africanos ao Brasil: evitava-se a formação de um grupo étnico numa fazenda ou em suas proximidades.

\section{As ganhadeiras na historigrafia}

No Brasil, o que era uma associação transformou-se em um título, cuja substância tinha a ver tanto com o comércio quanto com a religião. Essa mudança não impediu que surgissem as ganhadeiras-escravas ou forras, que permaneceram com o mesmo papel de mediadoras tanto de bens materiais quanto de bens simbólicos. A importância econômica da ganhadeira é atestada pela sua presença em várias cidades brasileiras. Na cidade de São Paulo, a presença das ganhadeiras é narrada por Maria Odila da Silva Dias:

Os observadores contemporâneos também descreveram negras de tabuleiros sentadas nas calçadas da rua da Quitanda Velha, durante o dia ou à noite, sob a iluminação fumacenta dos rolos de cera escura, pregados nos tabuleiros ou socados nos turbantes, quando caminhavam lentamente, jogando sombras pelo caminho. (DIAS, 1984, p. 14).

Não era só em São Paulo que se encontravam as ganhadeiras trabalhando, vendendo seus produtos, especialmente gêneros de primeira necessidade, para a população pobre da cidade. Em Minas Gerais, Luciano Figueiredo é o informante:

O destaque da presença feminina no comércio concentrava-se nas mulheres que eram chamadas de 'negras de tabuleiro'. Elas infernizavam autoridades de aquém e de além-mar. Todos os rios de tinta despejados na legislação persecutória e punitiva não foram capazes de diminuir o seu ânimo em Minas e pelo Brasil afora. (FIGUEIREDO, 1997,p. 145).

Há vários estudos que mostram a presença e a importância das mulheres de tabuleiro na Bahia, das comerciantes femininas, como o de Verger (1986); Landes (2002); Moreira Soares (1996) e Ferreira Filho (1998). Pierre Verger, ao comparar a rede africana das feiras com as que ocorrem nas Américas, afirma que

aqui houve a sua supressão, mas existem feiras locais (diurnas) e os "tabuleiros" das vendedoras isoladas (diurnas e noturnas). A baiana de turbante, camisa rendada, saias de algodão colorido sobrepostas e pano-daCosta, numa adaptação de vestimenta africana (ou melhor, das africanas muçulmanas) a um novo meio e novos "patterns" de vestuário - vai, com o tabuleiro sobre a cabeça, coberto, como em terra Nagô, por um pano que protege do sol e das moscas. Vai e se instala num canto da feira local, ou numa calçada, no ponto que lhe pertence de costume; ela senta num banquinho, põe ordem no tabuleiro e vende, aos apreciadores da comida africana, os acaçás, 
acarajés... Em alguns pontos da cidade, à noite, na luz vacilante dos lampiões, um grupo de baianas vende suas comidas ou pequenos objetos de perfumaria, recriando do outro lado do Atlântico a "feira noturna" dos vilarejos iorubas. (VERGER, 1992, p. 155).

A recriação da feira em Salvador é comentada também por Cecília Moreira Soares, que, referindo-se às escravas ganhadeiras, escreve:

O sucesso das ganhadeiras que se dedicavam à venda de peixe e de diversos gêneros, com renda diária de até 4 mil réis, em 1849, faz crer que souberam desempenhar seu papel muito bem. O sucesso se refletia, sobretudo, no controle que as ganhadeiras vieram a ter sobre o comércio varejista de produtos perecíveis. (MOREIRA SOARES, 1996, p. 61).

É claro que o fato de parte das escravas ganhadeiras terem comprado sua alforria não é o único responsável pela situação das mulheres negras serem alforriadas antes e em maiores proporções que os homens. Apesar da existência de poucos trabalhos sobre as relações de gênero durante a escravidão, Cunha demonstrou que, em termos de alforria, "houve discriminações: beneficiava-se primeiro, em extraordinárias proporções, as mulheres.” (CUNHA, 1985, p. 41).

Essas "ganhadeiras" dependiam de suas habilidades em lidar com a freguesia, atrair e conquistar com a qualidade de seus produtos e preços cômodos a clientela, e assim iam criando seus laços de sociabilidade com as diversas classes sociais. Cecília Soares afirma que essas mulheres, ambulantes ou trabalhando em pequenas quitandas, realizavam importante função de "harmonizar as duras condições da maioria escrava e dos desclassificados sociais", compradores assíduos dos seus produtos. A autora afirma que a liberdade de circulação e uma permanência nas ruas possibilitou para as negras a construção de um universo próprio, formado por elas mesmas, seus fornecedores e clientes, em "uma rede econômica que era também social e até política." (SOARES, 2010).

Esta modalidade de trabalho possibilitava aos escravos, homens e mulheres, maior liberdade e autonomia, já que muitos, devido aos lucros obtidos pelas vendas, poderiam "viver sobre si", saindo da casa de seus senhores e morando em cortiços nos arredores da cidade, e, mesmo que voltassem para a casa de seus senhores, ainda havia a possibilidade de criarem os mesmos laços pela liberdade de passar os dias nas ruas, buscando empregar-se em curto prazo em diferentes serviços. Apesar da despesa oriunda da moradia em outro domić́lio pelos escravos de ganho, a importância dessa atitude pelos mesmos estava atrelada à garantia de determinado espaço de autonomia para si, à medida que, longe dos senhores, estavam longe do controle direto exercido pelos mesmos e das variações de humor de seus proprietários (PALHA, 2011).

\section{As ganhadeiras: trabalho de poder e significado patrimonial}


A importância dessas trabalhadoras em Belém durante o século XIX era grande, elas se concentravam por toda a cidade em lugares fixos ou como ambulantes. Por mais que, durante a segunda metade do século XIX, tenha havido o crescimento da cidade de Belém nos seus variados aspectos, no contexto da crescente importância da borracha na pauta de exportação provincial e a riqueza daí gerada, colocava em questão a necessidade de melhor ordenamento e controle social do espaço urbano, pelo menos aos olhos das autoridades e das elites, ainda que os estudos sobre o processo de reurbanização da capital paraense se detenham basicamente no período da gestão de Antônio Lemos à frente da intendência municipal, na Primeira República, sem maiores preocupações com as décadas anteriores.

Essa reorganização demonstrava mudanças de hábitos evidenciadas por constantes exigências, por parte da população, em busca de construção de prédios e ruas pavimentadas (BEZERRA NETO, 2009). Eles também começaram a frequentar lugares com mais requinte como forma de imitar os costumes europeus. Segundo Sarges (2002, p. 13), "esse reflexo se expressa na construção de prédios como o Teatro da Paz, o Mercado Municipal do Ver-o-Peso, Palacete Bolonha, Palacete Pinho, criação de uma linha de bondes, instalação de bancos.". A cada dia, a cidade tomava novos ares com cafés, restaurantes e a construção de prédios elegantes.

Por outro lado, mesmo que os hábitos tenham mudado, após o boom da Borracha, ainda se convivia, nos fins do século XIX e XX, com velhos costumes e atividades profissionais, destacando-se, nesse caso, as vendedoras de quitutes, verduras e vendedoras de cheiro que trabalhavam livremente em diversos lugares de Belém e desempenhavam um importante papel no cenário local da época.

Segundo Macêdo (2008, p. 03), Belém contava com diversos tipos de estabelecimentos destinados à venda de alimento. Entre eles tabernas, vendas ambulantes, barracas, quitandas, cafés e restaurantes. Em cada um desses espaços, pessoas circulando, a vida acontecendo, bem como as disputas e tensões aflorando entre os sujeitos que buscavam fazer do comércio de comida esteio de sua sobrevivência ou até mesmo fortuna. Em sua pesquisa, a autora apresenta o comentário de um jornal Monarchista de 13 de março de 1852, que noticiava:

Em 1852, por exemplo, no dia 13 de março, na capital da província, o jornal O Monarchista Paraense publicou pedido dos taberneiros do $3^{a}$ Distrito da capital pedindo aos respectivos fiscais que redobrassem a vigilância sobre as quitandeiras, pois, eles que pagavam os direitos e impostos devidos para a venda de produtos nacionais e importados saíam no prejuízo já que aquelas além de não pagarem impostos "á sombra de meio dúzia de panellas, vendem todas ou quase todas, os mesmos gêneros que os taberneiros o não podem fazer, sem a competente licença...", até porque elas escondiam os produtos por traz das panelas. De imediato, podemos entender que taberneiros e quitandeiras não viviam na mais perfeita paz e que havia certo conflito entre ambas as categorias. 
Quanto à mesma atividade profissional e no mesmo período, Fernandes (2009) apresenta as mulheres vendedoras de banhos de cheiro de Belém do Pará, isso por meio de um estudo feito em algumas obras de arte feitas em pinturas de tela. Em meio a essas pinturas analisadas por Fernandes (2009), algumas delas eram de autoria da artista paraense Antonieta Santos Feio, e, segundo Fernandes, a presença das mulheres negras vendedoras de cheiro era uma imagem, nas pinturas em telas, muito frequentes, mencionando que a

Vendedora de cheiro é um retrato de meio corpo de uma mulher negra em perfil, vestida com blusa branca e saia florida, nos cabelos um indiscreto arranjo de flores brancas e vermelhas, compondo com os brincos, pulseira e corrente dourada no pescoço. Na mão direita segura um cesto de palha com cheiros de papel. Pode-se dizer que a imagem remete a uma figura bastante popular nas ruas da capital paraense desde o século XIX, como mostram as referências tanto de viajantes, como de escritores e artistas locais. A tela foi pintada em 1947 por Antonieta Santos Feio, que buscou no trabalho urbano de mulheres comuns a referência para sua obra. Particularmente, o trabalho das mulheres vendedoras, das quitandeiras, aparece repetidas vezes na produção de artes plásticas feita no Brasil, seja em aquarelas, gravuras e desenhos de pintores-viajantes, assim como em fotografias de cartões de visita do século XIX. (FERNANDES, 2009, p. 102-103).

O antropólogo paraense Napoleão Figueiredo (1988) desenvolveu uma importante pesquisa sobre o Ver-o-Peso, mais especificadamente, na área da etnobiologia, no que tange à utilização de animais, ervas e banhos em cerimônias religiosas, e na medicina popular em Belém do Pará e no interior do Estado, em que mostra a relação entre o sincretismo religioso e as práticas culturais desenvolvidas pela venda e consumo de tais produtos no mercado de Belém.

Em Belém, essa atividade profissional, hoje, denomina as vendedoras de cheiro como "Cheirosas" ou ainda como "Feiticeiras de Belém", qualificação essa que já foi manchete na imprensa nacional e em constantes reportagens nacionais e internacionais, especialmente devido ao exótico, à simpatia, às crendices, aos remédios para quase todos os males do corpo e da alma ${ }^{3}$.

Em Belém do Pará, no século XIX, as feiras públicas ganharam relevância na lógica das atividades de venda de produtos das drogas do sertão, que, em sua maioria, eram levadas para a exportação. A dinâmica da vida urbana, no decorrer do século XIX, estava intimamente ligada ao desempenho da economia local e regional, uma vez que o comércio serviu não apenas como atividade econômica, mas também possibilitou um maior dinamismo à vida social da cidade. Segundo Medeiros (2010), o surgimento das feiras livres em Belém reflete apenas um desses novos elementos. As feiras irão representar a relevância da atividade comercial, contemplando as primeiras necessidades da população menos favorecida da cidade, incluindo negros, mestiços e mulatos.

\footnotetext{
${ }^{3}$ Reportagem publicada na revista "Os caminhos da Terra" de 26/07/2006. No endereço eletrônico http:www2.uol.com.br/caminhosdaterra/reportagens/137_feiticeiras_de_belem.shtml.
} 
Nas feiras de Belém, as vendedoras de cheiros e garrafadas, estas compostas por diversas ervas tomadas pelas clientes e têm o poder de cura. Essas atividades, de fato, eram muito comuns, pois os jornais, como o Paraense, de 1835, trazia discussões sobre a venda de produtos para fazer banho de cheiro, que eram vendidos especialmente durante as festividades de São João. As pessoas faziam infusão em água das várias ervas, troncos de certas árvores e o patchulin e, com essa mistura, tomavam banho com a finalidade de atrair bons fluidos. Esse jornal, no dia 13 de junho do mesmo ano, noticiava:

As ruas e a feira do Ver-o-Peso já está cheia de produtos de banho de cheiro. As pretas e multasse preparam para vender seus produtos de casa em casa ou nas feiras, elas acreditam que nesse anno as vendas atingirão o máximo. Segundo dona Flor a procura já é grande mesmo nos dias que antecedem a festa de São João ${ }^{4}$.

Esse trabalho, desempenhado por tais atores sociais, foi ganhando amplitude de ano para ano, pois o jornal Monarchista, de 15 de junho de 1837, afirmava que a feira do Ver-o-Peso estava cheia do verde das ervas do banho de cheiro, que o jornal também chamava de "banho da felicidade". Ao que parece, essa atividade é algo bastante comum e aceitável pela população desde o século XIX, e, ao que tudo indica, a população não só aceitava a profissão, mas também usava tais produtos. No século seguinte, a pesquisadora Eneida de Moraes (1989) mencionava a importância desse produto nas feiras de Belém quando informa:

Cheiro cheiroso! (a pronúncia local: chêrochêroso!) Portas e janelas se abriam. Os homens paravam de casa em casa, desciam os tabuleiros; ervas, raspas, folhas, pedacinhos de madeira passavam de suas mãos às da compradora. Ninguém queria perder o direito à felicidade: ricos e pobres. Nos fogões e nas fogueiras - as mesmas que iriam iluminar a noite do santo - a grande lata fervia, com vegetais perfumados da Amazônia que, ralados, esmagados, verdes pela juventude ou amarelecidos pela velhice, dão, depois de fervidos, um líquido esverdeado com o exuberante perfume da mata virgem. (ENEIDA DE MOARES, 1989, p. 198).

Além dessas vendas de banho de cheiro, o jornal Paraense do ano de 1937 noticiava a venda das chamadas garrafadas, "produtos que promovem cura de algumas moléstias". Esses produtos eram produzidos pelas próprias mulheres que os vendiam. As garrafadas eram produzidas utilizando a combinação de várias ervas terapêuticas que, em conjunto, servem para o tratamento de algumas doenças. Esses produtos sempre foram vendidos livremente nas feiras de Belém e consumido pela população belenense e também por pessoas de outras cidades paraenses. Segundo o noticiário deste jornal:

${ }^{4}$ O Paraense, 13/06/1835, n.o 1024, p.4; Arq.CMC, cx. C6/7, pasta 1830, 13/06/1835 
A senhora de nome Sebastiana Assunção estava anunciando que estava trabalhando com a venda, de porta em porta das ruas da cidade velha, com garrafadas que continham produtos bons para azia, dores no baço, infecções de útero ou estomacais, conter hemorragias e inflamações, além de garrafadas que serviam para evitar filhos e lavar o útero depois de ter parido. Elas também vendem esses produtos na feira do Ver-o-Peso todas as manhãs nas bancas ${ }^{5}$.

Sendo assim, a venda de cheiro e das garrafadas terapêuticas eram, durante o século XIX e $\mathrm{XX}$, aceitas pela população e pelos próprios órgãos públicos, pelo menos ao que parece nos jornais da época. Através do Decreto Municipal 26.579, de 14 de abril de 1994, afirma-se que os produtos de varejo e alimentos deveriam ser vendidos em um local específico que, nesse caso, seriam as feiras:

Art. $1^{\circ}$ - Considera-se "Feira Livre" o local previamente designado pela administração Pública Municipal, dotado de equipamentos padronizados, removíveis ou não, destinados as atividades comerciais a nível de varejo, voltada para o abastecimento de gêneros alimentícios a população, especialmente os de origem hortigranjeira. (BELÉM, 1994, p. 39 ).

O processo de regularização e fiscalização dos espaços de feiras em Belém ainda é algo bastante complexo, tanto para quem participa ativamente da vida da feira, quanto para quem deveria fiscalizar. Isso porque, nos últimos cinquenta anos, verificou-se uma grande expansão do número de feiras livres na capital paraense (MEDIROS, 2010).

Os jornais em nada falavam sobre uma possível proibição de venda dos cheiros e das garrafadas muito famosas do mercado do Ver-o-Peso, não posso afirmar se eram legalmente aceitos ou se os órgãos públicos não possuíam nenhum decreto que fosse contra ou a favor de suas comercializações. O certo é que, durante o século XIX, foi muito trabalhado e de certa medida utilizados com fins ritualísticos, como o caso de Josefina Fontes, que apareceu no Jornal Paraense de 1852, sendo acusada de comprar algumas ervas para fazer feitiços.

O jornal A Voz do Guajará, de 12 de fevereiro de 1905, enfatiza uma breve denúncia de certa Dona Carmem, mulher preta, com cerca de 35 anos de idade, que diariamente comprava ervas, lascas de paus, perfumes aromáticos, amoníaco e outros produtos que, segundo o acusador, relatado no jornal, servira para práticas de curandeira ou feitiçaria, demonstrado que as práticas religiosas afro-ameríndias já se faziam presentes desde o século XIX, ratificando assim, a tese de Aldrin Figueiredo (2008), em que o mesmo afirma a existência de pajés, ou possivelmente de pais de santo em Belém desde o mesmo século.

Toda essa análise pode ser reiterada quando observamos a nota do Jornal Diário do Pará, em 22 de dezembro de 1956, em que o mesmo, em nome dos vendedores de cheiro e ervas do mercado do Ver-o-Peso, informava a população sobre a aquisição de novos materiais de Umbanda

\footnotetext{
${ }^{5}$ Jornal O Paraense de 02/09/1937. 
para os que faziam obrigações de final de ano ${ }^{6}$. Essa nota jornalística é muitíssimo relevante, pois acaba por demonstrar que, em certa medida, esses vendedores possuíam alguma ligação com pessoas do santo, ou seja, com pessoas ligadas às religiões de matriz africana em Belém naquele período. Nesse sentido, as feiras livres comportam-se como verdadeiros "espaços residuais" (LEFEBVRE, 1999), diante da plenitude das formas urbanas complexas que marcam comportamentos sociais, na maioria dos casos, estranhos à realidade local.

Cria-se também, a partir da existência desses espaços, uma imagem da cidade. Isto é, a dita cidade ribeirinha passa a se expressar a partir dos elementos e das relações sociais construídas no presente das feiras livres do lugar. Tais espaços carregam um significado que transcende o aspecto comercial, chegando mesmo a expressar significados socioculturais capazes de estruturar diferentes cotidianos na cidade.

A feira livre marca sua existência cotidiana na cidade, reforçada pela condição histórica, pela sua localização geográfica, pela quantidade de feirantes e pela diversidade de iguarias à disposição de todos aqueles que fazem desse espaço um ponto de reafirmação de identidade e de autonomia sociocultural.

\section{Mulher, trabalho e permanência: as ganhadeiras de Belém}

Diante do levantamento de dados em jornais do século XIX, especialmente entre os anos 1830 a 1890, foi possível perceber o real valor dessa atividade profissional que ainda hoje se mostra com uma incomensurável importância econômica e social. No ano de 1875, o Jornal Diário do Pará trazia a notícia que haviam chegado novos produtos que serviam como amuletos e incensos, além de certas ervas que estavam faltando há alguns dias.

Senhora Fátima Vasconcellos está anunciando aos seus fregueses que chegou a sua banca de vendas, situada no mercado do Ver-o-Peso, vários artigos que estavam em falta, como: amuletos e banhos atrativos de amor e de emprego vindo do Maranhão. Além de novas ervas que servem para fazer banhos específicos ${ }^{7}$.

No mesmo ano e no mesmo jornal, mas no dia 22 de maio, foi dada a notícia à população belenense que a senhora Luíza Carmem avisava que havia chegado novo estoque de ervas e,

\footnotetext{
${ }^{6}$ Algo que pode responder à presença deste noticiário pode estar pautado na maior liberdade que a Umbanda já possuía no Brasil durante este período, se comparado com outras religiões de matriz africana como o candomblé que era comumente estigmatizado e até mesmo proibido de professar seus cultos por ser considerado demonizado. A Umbanda era mais aceita devido à tentativa de "branqueamento" que essa religião sofreu com o intuito de ser aceita. Esse branqueamento estava relacionado com a retirada de algumas entidades que eram consideradas símbolos do demônio cristão, como os Exus; a não permissão de matar animais para sacríficos; além de extrema ligação com o kardecismo (ORTIZ, 1999).

${ }^{7}$ Jornal Diário do Pará, de 15 de Abril de 1875.
} 
também garrafadas, e segundo o anúncio do jornal Diário do Pará, era excelente terapêutico para infecções em geral. Na Voz do Guajará, de 30 de maio de 1862, afirmava-se que as garrafadas e os materiais do banho de cheiro estavam disponíveis nas feiras de toda a cidade de Belém. O jornal $\mathrm{O}$ Paraense, de 04 de junho de 1862, também trazia no meio de seus informes que

O mês de junho desse ano está mais "cheiroso" do que nunca, porque agora as vendedoras e vendedores do produto começaram a trabalhar também nas outras feiras de Belém, na feira do Guamá e no Jurunas. Já avisam o povo de Belém que seu estoque está completo.

Outro dado interessante veio do Jornal Liberal, de 16 de fevereiro de 1952, em que o mesmo trazia anúncios, com muito entusiasmo, sobre várias pinturas em tela que haviam sido expostas na cidade. Esse evento, de acordo com o jornal, era de suma importância para a vida cultural do povo de Belém, que passava a gozar de estilos e gostos semelhantes aos dos europeus. Seja como for, uma das telas trazia informações sobre uma vendedora de cheiro que, provavelmente, trabalhava nas ruas de Belém.

Dessa forma, de acordo com os jornais da época os produtos vendidos, normalmente adquiridos no interior do Pará, eram plantas medicinais (folhas, seivas, extratos, cascas, raízes, infusões), óleos, banhos, essências, perfumes, sementes, garrafadas e remédios, e tinham como finalidade basicamente a medicinal e a mística (que inclui o religioso).

O que pode se inferir é que essa atividade em Belém foi, durante o século XIX, aceita ou até bem vista pela população da época, pois poucas eram as denúncias contrárias a sua circulação e venda. Diante disso, se não for apressada, posso até questionar se essa atividade profissional e os seus produtos não são na verdade um ponto da cultura belenense.

Nesse sentido, os espaços de feiras livres podem (e devem) ser entendidos como um produto da formação e expansão do espaço urbano em Belém. Além disso, são espaços que resguardam um pouco da cultura local/regional. Tidos mais como "espaços residuais" do que como espaços complementares à dinâmica de funcionamento do circuito superior da economia, esses locais expressam a sua singularidade numa região em que "fazer-a-feira" não marca apenas uma tradição na vida cotidiana de muitas famílias, mas, sobretudo, um momento de encontro, de reencontro e de possibilidades múltiplas para a realização da vida cotidiana no mundo contemporâneo.

As feiras livres em Belém, caracterizadas como espaços de possibilidades para a criação ou para a manutenção dos traços regionais e locais, permitem ao homem comum, aquele que vive grande parte dos momentos de sua vida, a sua projeção no espaço da cidade, a ser sujeito de sua própria história, que, em muitas oportunidades, foi vivida por outros agentes, às vezes, do mesmo tronco familiar.

Do ponto de vista cultural, esses espaços se voltaram para a manutenção das tradições e dos hábitos locais. A valorização do saber tradicional, a partir da manifestação de práticas cotidianas 
movidas pela comercialização de ervas e artesanatos, por exemplo, possibilita o reforço da memória sobre o espaço e o lugar.

É nesse sentido que Almeida (2011) avalia, em sua definição teórica, que os defumadores, as "Limpezas", "Ebós de Saúde" e "Sacudimentos", os banhos de ervas, de "Abô", de mar e de cachoeira, as preces, os cânticos e danças são considerados, em conjunto, ações terapêuticas. Estas são consideradas igualmente importantes aos medicamentos de origem vegetal de ação sistêmica pelo doente afligido por males físicos, mentais ou espirituais. Todas essas ações são consideradas "remédios" objetivando a cura. Sendo assim, o conhecimento dessas vendedoras pode ter ligações com os africanos ou descendentes de africanos que já residiam na Amazônia desde o século XVII, quando das primeiras levas do tráfico negreiro (SALLES, 1988).

Maria Zélia Almeida (2011) afirma que as plantas estão sempre presentes através do uso das folhas, raízes, frutos e das árvores de várias representações simbólicas, bem como outros elementos naturais, insetos, cinzas, ossos, ovos e muitos outros objetos utilizados para a cura e prevenção de doenças. Uma pessoa doente, ao beber um chá de uma determinada folha, deve sorver acreditando não somente nas propriedades medicinais químicas e/ou farmacológicas da planta, mas também no seu poder mágico ou espiritual.

A Portaria n. 212, de 02 de setembro de 1991, já referida, define como áreas prioritárias em plantas medicinais: 1. Estudos de identificação, avaliação e controle de preparações fitoterápicas oficiais e de uso popular generalizado. 2. Estudos botânicos, farmacotécnicos e químicos de preparação fitoterápica, com vistas a definições de métodos de preparo, doseamento de princípios ativos e controle da qualidade. 3. Desenvolvimento de ensaios farmacotécnicos para avaliação das propriedades terapêuticas das preparações farmacêuticas de uso popular obtidas de plantas medicinais. 4. Esquadrinhamento farmacológico e fitoquímico de espécies selecionadas da flora brasileira e outros produtos.

Mesmo que tivessem portarias e decretos sobre a produção de remédios fitográficos que atingissem o território brasileiro como um todo, em Belém do Pará, durante os anos de 1830 a 1990, não havia portarias que proibissem ou que limitassem a venda ou o uso de tais produtos. As portarias, em Belém, que têm o intuito de melhorar a venda e produção, só vão ser feitas pelos fins do século XX. Por essa razão, a produção de tais produtos ficaram livres e sem físcalizações.

As denúncias que apareciam nos jornais não faziam referência à venda das ervas e das garrafadas propriamente falando, mas sim dos fins para os quais os produtos eram utilizados, em que geralmente se denunciavam pessoas alvo de acusações por terem feito feitiço ou bruxaria para conquistar algo, e, os produtos adquiridos na feira eram a prova do dito crime. O Jornal A Voz do Guajará, de 02 de novembro de 1893, trazia uma nota interessante a esse respeito:

A denúncia de Dona Maria de Fátima afirma que uma mulher preta, alta de mais ou menos 28 anos de idade, chamada Fátima Silva de ter feito feitiço para "amarrar" (prender de maneira espiritual) seu filho Alfredo Costa. E os 
sintomas são os seguintes: o rapaz não tem vontade de fazer nada, fica dormindo o dia todo e fica chorando por essa mulher! E Dona Maria afirma que a prova desse crime seriam compras feitas por Fátima Silva em uma certa banca de ervas na feira do Ver-o-Peso, em que Dona Maria confirmava ter visto a referida mulher ter saído com várias sacolas de compras daquele lugar.

Almeida (2011) também traz a mesma discussão quando menciona que

Pode-se ilustrar o fato com antigos recortes de jornais como a manchete do Diário de Notícias de Salvador, de 09 de maio de 1905: "Rapariga de família enlouquece com a beberagem de Jurema no Candomblé" (ALMEIDA, 2011, p. 45-46, grifo meu).

Assim, este projeto tem relevância por apresentar uma proposta de analisar com mais afinco os documentos, que, em pequeno número, já estão disponíveis neste trabalho, e que contribuem com a historiografia paraense e brasileira, pois, quando nos remetemos às pesquisas de referência a este período, pouco encontramos informação, através dos documentos, de como eram o trabalho, os conflitos, as vendas, os locais de distribuição, a relação dos trabalhadores com religiões de matriz africana ou indígena ou ainda em que medida era mesmos aceitos pela sociedade paraense.

Por essa razão, entendo ser um projeto de relevância acadêmica e social, pois busca entender como o trabalho dos erveiros ou das quitandeiras sobreviveu entre os anos de 1830 a 1990 em uma sociedade na qual, segundo Sarges (2002), convivia com o moderno vindo sob os moldes europeus devido à busca de afirmação de uma nova elite que estava rica, pelo dinheiro advindo da produção da borracha, e, ao mesmo tempo, convivia com práticas culturais antigas, como os banhos atrativos ou banhos de cheiro, ou ainda com o consumo de garrafadas terapêuticas. Isso mostra que, talvez, o moderno não tenha se desatrelado dos antigos costumes como se esperava.

Assim, essas práticas comerciais ou profissionais podem ratificar que o Pará, durante esse período, já convivia com práticas de cultos de religiões de matriz africana ou de práticas ligadas à pajelança indígena, que já se faziam presente desde muito tempo em terras amazônidas. O trabalho do historiador paraense Aldrin Figueiredo (2008) nos dá uma pista para essa assertiva quando demonstra a presença de certo Sátiro a quem, frequentemente, o autor encontrava nos jornais com seu nome ligado a alguma denúncia policial com a acusação de realizar práticas de feitiçaria ou bruxaria. A pergunta que o pesquisador fazia, naquela ocasião, era: será que na Amazônia já havia práticas de religiões de matriz africana ou o que Sátiro realizava era a pajelança? Ou ainda, Sátiro seria um pajé ou um pai de santo?

\section{Considerações finais}

O trabalho desenvolvido pelas chamadas erveiras ou cheirosinhas das feiras públicas de Belém do Pará nos mostram que esta é uma atividade eivada de mudanças e permanências, sendo 
elas as mais diversas, desde a mudança temporal até a mudança geográfica. Isso, devido aos vários lugares em que essas personagens têm atuado ao longo do tempo até chegarem ao mercado do Vero-Peso, lugar onde hoje elas possuem um grau de importância que vai além da simples comercialização das ervas, chegando ao nível simbólico, religioso e turístico.

As erveiras e seus produtos se mostram como um verdadeiro pilar de sustentação de um imaginário sócio religioso ao longo do tempo, uma vez que para os pajés, bem como para os afroreligiosos, seus trabalhos de cura e encante se iniciam com a utilização de tais produtos, que, por essa razão, são tão comuns em Belém do Pará ao longo dos séculos, e, nos dias de hoje, configuramse como um forte elemento cultural do cartão postal da Capital do Estado do Pará.

Assim, este trabalho tentou apresentar o trabalho das erveiras, mulheres que trabalhavam com ervas, produtos vendidos nas feiras de Belém entre os anos de 1830 a 1890, que são até hoje utilizados em rituais de Umbanda, Candomblé ou de Mina Nagô em Belém. E, além disso, são incorporados pela população belenense como todo, ou seja, independente da religião e vai muito além chegando até mesmo a ser fortemente apreciado em várias cidades do interior do Estado do Pará e Brasil, além dos crescentes preferencias de tais produtos por parte de clientes estrangeiros.

\section{Fontes}

\section{Fontes Manuscritas:}

\section{Arquivo Público do Estado do Pará:}

Biblioteca:

Jornal O Paraense, de 13/06/1835, n. ${ }^{o} 1024$.

Jornal Monarchista, de 15 de junho de 1837.

Jornal O paraense, de 02/09/1937.

Jornal A Voz do Guajará, de 12 de fevereiro de 1905.

Jornal Diário do Pará, de 15 de Abril de 1875.

Jornal Diário do Pará, de 22 de Maio de 1875.

Jornal Voz do Guajará, de 30 de maio de 1862.

Jornal A Voz do Guajará, de 02 de novembro de 1893.

Jornal Liberal, de 16 de fevereiro de 1952.

Jornal Diário do Pará, em 22 de dezembro de 1956.

\section{Arquivo Público do Estado do Pará (Belém):}

Relatórios de governo: Decretos: 
Decreto Municipal, n 26.579, de 14 de abril de 1994, que institui a proibição de certos alimentos e produtos varejistas vendidos nas feiras públicas de Belém, Belém, 1994.

Relatórios de governo (Brasil):

Resolução CIPLAN n. 08/88 normatiza a implantação da Fitoterapia nos serviços de Saúde nas Unidades Federais.

Portaria n. 212, de 02 de setembro de 1991.

Página da internet:

Revista: "Os caminhos da Terra" de 26/07/2006. No endereço eletrônico http:www2.uol.com.br/caminhosdaterra/reportagens/137_feiticeiras_de_belem.shtml.

\section{Referencias}

ALMEIDA, Mara Zélia de. Plantas medicinais. - 3a . ed. - Salvador : EDUFBA, 2011.

BEZERRA NETO, José Maia e MACÊDO, Sidiana da C. Ferreira de. A QUITANDA DE JOANA E OUTRAS HISTÓRIAS: os escravos e as práticas alimentares na Amazônia (séc. XIX). In. Histórica - Revista Eletrônica do Arquivo Público do Estado de São Paulo, no 38, 2009.

BEZERRA NETO, José Maia. Mercados, conflito e controle social. Aspectos da escravidão urbana em Belém. In: História \& Perspectiva, Uberlândia, jul,dez, 2009.

CANEVACCI, Massimo. Sincretismos. São Paulo, Studio Nobel, 1996.

CARLOS, Ana Fani Alessandri. A metrópole entre o local e o global. In: SILVA, Catia Antônia da; CAMPOS, Andrelino. (Org.) Metrópoles em mutação: dinâmicas territoriais, relações de poder e vida coletiva. Rio de Janeiro: Revan; FAPERJ, 2008, p. 131-153.

CUNHA, C. Mariano. "A feitiçaria entre os nagô-yorubá". In: Dédalo, vol. 23. São Paulo, USP, 1985.

FERNADES SILVA, Caroline. $O$ moderno em Aberto: $\mathbf{O}$ mundo dasbelas artes em Belém do Pará e a pintura de Antonieta Santos Feio. Dissertação de Mestrado. Universidade Federal Fluminense, Programa de Pós Graduação em História Social. Niterói, 2009.

FIGUEIREDO, Aldrim Moura de. A Cidade dos Encantados: Pajelança, Feitiçaria e Religião Afro-Brasileira na Amazônia, 1870 - 1950. Belém: EDUFPA, 2008.

Anfiteatro da Cura, Pajelança e Medicina na Amazônia no limiar do século XX. IN. Artes e Ofícios de Cura no Brasil: capítulos de história social/ Sidney Chaloubet al (Org). Campinas, SP. Editora da UNICAMP, 2003. 
. "Anfiteatro da Cura, Pajelança e Medicina na Amazônia no

limiar do século XX". IN. Artes e Ofícios de Cura no Brasil: capítulos de história social/ Sidney Chaloub et al (Org). Campinas, SP. Editora da UNICAMP, 2003.

FIGUEIREDO, Luciano. "Mulheres nas Minas Gerais". In: História das mulheres no Brasil. São Paulo, Contexto, 1997.

FIGUEIREDO, Napoleão. Os bichos que curam: os animais e a medicina do "folk" em Belém do Pará. Boletim do Museu Emílio Goeldi. Série Antropologia. Belém, v. 10, nº 01, p. 75-91, 1988.

LANDES, Ruth. A cidade das mulheres. $2^{a}$ edição. Rio de Janeiro: Editora UFRJ, 2002. . "Escravidão de Negro e Estado Feminino". Negócios africanos, vol 9, 1953.

LEFEBVRE, Henry. A revolução urbana. Tradução de Sérgio Martins. Belo Horizonte: UFMG, 1999.

LUCA, Taíssa Tavernard. Revisitando o Tambor das flores: A federação espirita Umbandista dos Cultos Afro-brasileiros em Belém do Pará. Dissertação de Mestrado. Departamento de Antropologia, Universidade Federal de Pernambuco, UFPE. Pernambuco.

MACÊDO, Sidiana da Consolação Ferreira de. Os sabores da cidade: práticas alimentares, hierarquias sociais e seus lugares em Belém do Pará, segunda metade do século XIX. In Seminário Temático 15 XIX Encontro Regional de História da ANPUH. São Paulo, 2008.

MEDEIROS, Jorge França da Silva. As feiras livres em Belém (Pa). Dissertação de Mestrado. Universidade Federal do Pará, Instituto de Filosofia e Ciências Humanas, Programa de PósGraduação em Geografia, Belém, 2010.

MORAES, Eneida de. Aruanda e Banho de Cheiro. Belém: Secult / FCPTN, 1989, p. 198.

MARTINS, José de Souza. (Org.). (Des)figurações: a vida cotidiana no imaginário onírico da metrópole. São Paulo: HUCITEC, 1996.

ORTIZ, Renato. A morte branca do feiticeiro negro: umbanda e sociedade Brasileira. São Paulo: Brasiliense, 1999.

PALHA, Bárbara da Fonseca. História de trabalhadoras escravas na Belém do século XIX. Anais do XXVI Simpósio Nacional de História-ANPUH, São Paulo, julho, 2011.

PANTOJA, Ana Lídia Nauar. Mulheres negras em Belém do Pará: política públicas e estratégias de sobrevivência (1890-1910). Dissertação de mestrado. Universidade Federal do Pará. Núcleos altos de estudos Amazônicos. Programa de pós Graduação em Desenvolvimento Sustentável e Tópicos Úmidos. Belém, 2001.

PANTOJA, Selma. As mulheres na formação do mundo Atlântico e a história de Angola dos séculos XVIII e XIX. In. Revista Humanidades. Nº 01, novembro, 1999. 
PENTEADO, Antônio Rocha. Belém: estudo de geografia urbana. Belém: UFPA, 1968, 2 v. (Coleção Amazônica).

SALLES, Vicente. O negro no Pará: sob o regime da escravidão. Belém / Brasília: Secult / Ministério da Cultura, 1988.

SARGES, Maria de Nazaré. Belém: produzindo a Belle-Époque (1870/1912). Belém: Paka-Tatu, 2002.

SOARES, M. Cecília. "As ganhadeiras: mulher e resistência negra em Salvador no século XIX". In: Afro-Ásia, vol. 17. Salvador, CEAO-UFBA,1996.

VERGER, Pierre. "A contribuição especial das mulheres ao candomblé do Brasil". In: Culturas africanas. São Luís do Maranhão,UNESCO, 1986.

VERGOLINO, Anaíza. O Tambor das Flores. Dissertação de Mestrado. Departamento de Filosofia e Ciências Humanas, Mestrado em Antropologia Social. São Paulo: UNICAMP, 1976. 